\title{
Exploration and Analysis on PE Teaching and Reform from the Perspective of Universities and Colleges
}

\author{
Bin Cao \\ Shandong Women's College \\ Jinan, China
}

\author{
Qun Niu \\ Shandong Vocational College of Foreign Affairs \\ Translation \\ Weihai, China
}

\begin{abstract}
In recent years, there are obvious downtrends for the physical and psychological quality of China's college students. By investigation, the objective of China's college sports teaching is unclear, so it's difficult to establish the thought of lifelong physical exercise, and the physical education courses of many colleges in China also are carried out in "formalization". Therefore, it's necessary for China's colleges and universities to establish correct physical education thinking and objective.
\end{abstract}

Keywords-physical education of college; thinking of physical education; reform of physical education

\section{INTRODUCTION}

Physical education is a main foundation and channel of universities and colleges' physical education, which is a public compulsory course that mainly considers rational physical education and scientific physical training as the process and can reach the objectives of strengthening students' physique, building up physical health and enhancing students' physical attainment; Physical education is an important constituent part in universities and colleges' course system while extracurricular physical education is also an important constituent part in universities and colleges' physical education curriculum, which is the supplement and expansion except physical education class, and also an important approach and means of realizing physical education.

\section{Teaching Mode Of College Sports Classes}

In essence, physical education course is a kind of stable and mature process of physical education. Through chronically consulting relevant data and teaching practice, the current teaching mode of national and foreign physical education class mainly has :

- The mode of PE education of micro-community study.

- Situation and mode of simulating physical education.

- The mode of discovering-type physical education.

- Focus on the mode of physical education for students who experience sport enjoyment.
- Focus on the mode of physical education for doing exercise during teaching process.

- Focus on the mode of letting students experience successful physical education.

- Focus on the mode of students' initiative physical education.

\section{THE FACTORS INFLUENCING EFFECTIVE TEACHING}

\section{A. University and College Lack Specific Educational} Objective and Fitness Ideas

In the current furious social market competition and during the work-seeking after graduation of China's undergraduates shall endure the very big employment pressure and life pressure, so they shall have an ability of a healthy body and strong psychological endurance, but according to investigation we can find that in current years there is an obvious decline trend in students' physical fitness and psychological quality. Investigating reasons, which is that the objectives of China's teaching of physical education in colleges and universities is not specific, so it's difficult to help students establish the thought of lifelong physical exercise, so after students step up employment positions, they ignore the exercise of body often because of the high pressure from work and busy tasks. Even if when students attend classes, but because of the pressure of many aspects like specialized courses and tasks, many students also often don't attach importance to physical exercise, so China's many PE courses of universities and colleges come close to the status of "formalization" and it's necessary to establish right PE teaching thought and objectives in China's universities and colleges.

\section{B. The Relationship between Teaching Content and Students}

PE teaching is a bi-directional, complex and multilateral activity. In order to teach physical education class well, teachers shall know about the sports skill and physical knowledge level of students, and choose the course content that are suitable to the need of students' technological level and physical \& mental teaching, and course teachers shall select the teaching content which students haven't studies previously and are challenging but students can reach the 
requirement through study, only by this develop the dominant role of students can students enjoy the pleasure of participating in exercise ability and promote the comprehensive development of students' constitution and mind \& body.

\section{The Relationship between PE Teachers and Students}

For the effectiveness of physical education, in addition to students' study, the PE teacher, as the guide of a lesson, is more critical, and teachers shall continuously increase their organization and management ability and they shall skillfully and scientifically guide students to orderly and independently study and do exercise, which are the premise and origin of organizing effective teaching, and the teachers with relatively high ability can smoothly conduct effective teaching. We shall put more emphasis on the effectiveness of everyday physical education, and the effectiveness of everyday PE teaching is long-term and effective, which is the final objective of our PE education. How to teach students to actively do exercise in their spare time except physical education class, which is a difficult point and is also our teaching's emphasis, and an effective physical education class is to teach students basic exercise skills and let students cultivate the habit of lifelong exercise so reach the objectives of national fitness.

\section{Strengthen the Construction of Teaching Staff}

Increase the educational background structure of physical teaching staff. Because of the rapid advance of science and technology, it's more important to promote the knowledge elements of physical education teachers, and under China's new circumstances, the educational requirements of $\mathrm{PE}$ teachers of universities and colleges also gradually increase, while comparing with the development level of other professions, the development level of China's physical education lags behind seriously, and the overall education level of PE teachers of universities and colleges are relatively low, and the number of PE teachers who have Doctor's degree is very few, so it's very important to increase the educational background structure of PE teachers of universities and colleges. PE teachers all know their own objective of the struggle, encourage teachers to assiduously study academic degree and participate in academic discussion, and advocate the training of going out for study and teaching skills. Strengthen the training of forgoers of physical education and backbone teachers, and regularly conduct the evaluation of forgoers of physical education and backbone teachers and actively motivate the standing out of young teachers so as to drive the development of physical education.

\section{E. Increase the Investment of Teaching Expenditure and Improve the Sports Ground}

The development of China's educational business is rapid, and the enrollment scale is gradually enlarged, and the area of sports ground of colleges \& universities and equipment facilities is in relative shortage, because of the restriction of sport equipment, some students lost the opportunity of doing physical exercise and cannot guarantee school education, especially the normal high-quality process of physical education, good places \& equipment and class-attending environment, which will enhance the will, confidence, emotion, interest and exercise capacity, and there shall be good material bases as guarantee for the reform of physical education and education, and sports ground and equipment facilities are a very basic material basis, so increasing the continuous investment of physical education funding, and updating sports equipment facilities play a very important role in increasing the quality of physical education, so make full use of existing place and equipment \&facilities and according to the need of teaching, designedly construct sites, add equipment \&facilities to let many students, according to their own interest characteristics, more widely select the content and form of physical education and exercise to meet the need of bodybuilding and mental health. In order to ensure the smooth proceeding of school physical education, we shall strengthen the management of the site and equipment \& facilities, establish relatively strict storage system of physical equipment $\&$ facilities, and increase the utilization of sports ground and equipment $\&$ facilities.

\section{F. Strengthen the Continuous Education and In-Service Training of Physical Education Teachers}

Physical education brings forward higher requirements of gym teachers, especially the change of their structure of knowledge. Teachers not only have sports expertise and skill and also have knowledge of health care and health. Under the current social environment, educates come up with severe challenges for gym teachers. Physical education not only promotes the physical development of students and cultivates the mental health of students, which requires gym teachers to study continuously, and actively participate in the training of vocational skills, and master the latest subject knowledge which is suitable to the development of modern society.

\section{The ImPlementation Of Teaching Methods And} MEANS Is AN IMPORTANT CONTENT OF DEEPENING PHYSICAL EDUCATION REFORM

The implementation of sports teaching method shall be shifted from exam-oriented education to overall quality education, and shifted from the impartation-mode education of knowledge to the intelligent-type and physical-type education of quality of the whole people, which is the crux of increasing physical education quality, and is the touchstone of examining the teaching level of teachers' physical education, and is an important manifestation of constructing high-level teacher team.

\section{A. Teaching Method of Contrastive Type}

Physical education class is a kind of method by which physical education teacher knows about the completion situation of the basic quality, specific quality and teaching content of students. According to the differences between students, in classroom teaching, in accordance with students' physical fitness, teachers select content of courses, and meantime, teach students to increase the method of increasing physical fitness. The teachers giving a class can adopt multilevel comparison and contrast such as the comparison and contract of correction and error, the comparison and contract of similar technology, the comparison and contrast between groups, and the comparison and contrast between front row 
and back row. The form and teaching method of teaching organization will more effectively increase the teaching quality and effect, and enable students to study and master technology and athletic movement, and meantime, help students learn from each other; is also convenient for the development of competition activities in learning to let teachers and students collectively know about, master and increase the methods of the exercise capacity and level.

\section{B. Teaching Method of Permeation Type}

Put the learned content in physical education into the active mini-game and competition to increase the level of sport technique, skills and athletic ability of students, and by doing this the effect from complex to simple and from difficulty to simplicity will generate, which motivates the interest of study and activity of students, and also cultivates the spirit of students' collectivism, and gives play to students' pro-activity and creativity.

\section{Teaching Method of Marking Type}

Setting marks is a kind of very effective teaching method in physical education, which plays a very important role in helping students can correctly experience and master the action essentials, form the correct action idea and action setting, which can better and quickly finish the teaching tasks.

\section{Teaching Method of Decomposition and Combination Type}

That is to say, in physical education, according to the complexity of teaching content, and the physical fitness and skill base degree of students, teachers divide the high difficult elements of sport technique into several single movements, and combine them into a complete movement.

\section{NON-DisCRIMINATORY EDUCATION OF COLLEGES AND UNIVERSITIES' TEACHING}

The project non-discriminatory phenomena of physical education curriculum is that modern people praise highly, and there exist many in universities and colleges' teaching, and for the projects of many physical education curriculum, implement "one size fits all", no matter male and female studies the same sport event, and use the same standard to evaluate the final result without considering the difference of sex between male and female which exerts the different influence on sports movement effect, which makes the final result certainly will, to a large extent, influence the pro-activity of students' study, and for cultivating their interest in sports activity and exercise habit, many negative effects can also generated. However, at present, many universities and colleges still adopt this kind of mode, the reason of which is that this kind of mode of attendance is easily to be managed and the students' original classes need not be disorganized, not only working personnel of educational administration system but also teachers attending specific classes all adopt this kind of mode of attendance, but provide sport event of different choices not according to students' gender characteristics and different projects of physical education curriculum are set not according to students' hobbies and interests, so under the teaching mode of physical education curriculum whose sport events have no differences, the enthusiasm and pro-activity of students who participate in athletic activities are greatly influenced.

\section{CONCLUSION}

There are many ways to gradually increase the teaching methods of college physical education, and as long as we earnestly research and practice and actively explore these ways, we can make students to like physical education really and increase the effectiveness of sports classrooms and really reach the ultimate aim of "happy physical education and lifelong physical education". Therefore, only full completion of the teaching tasks of physical education does promote China's quality-oriented education and national fitness, which is the sacred responsibility of every physical education teacher.

\section{REFERENCES}

[1] Xu Wei. Humanistic Education Theory and Practice Research on College Sports[D]. Beijing Sport University, 2013.

[2] Du Yanfeng. Simple Discussion on How to Increase the Effective Teaching of Physical Education Class [J]. Youth Liberator, 2009.

[3] Zhou Zhigang. Discussion on the Embodiment of Humanistic Spirit in Physical Education of Universities and Colleges [J]. Time Education (Education and Teaching Edition), 2009(9).

[4] Zhao Qin'an Factors and Countermeasure Research Influencing the Teaching Quality of University Education [J].Private Science and Technology, 2013(9). 